\title{
Re-evaluating the environment in developmental evolution
}

\author{
Armin P. Moczek* \\ Department of Biology, Indiana University, Bloomington, IN, USA
}

\section{Edited by:}

Stefano Tiozzo, Centre National de la Recherche Scientifique - Sorbonne Universités - UPMC, France

Reviewed by:

Amro Hamdoun, Scripps Instituion of Oceanography, USA

Lucas Leclere, Centre National de la

Recherche Scientifique - Sorbonne

Universités - UPMC, France

${ }^{*}$ Correspondence:

Armin P. Moczek, Department of

Biology, Indiana University, 915 East

Third Street, Bloomington, IN

47405-7107, USA

e-mail:armin@indiana.edu
This manuscript reviews our growing understanding of the role of environmental conditions in shaping development and developmental evolution. It then discusses how this enhanced understanding increasingly questions our intuitive notions of the environment as separable from-and external to-organisms, as a selective force that is passive rather than generative, and as an external agent that organisms respond to, rather than one that organisms actively modify to suit their responses. Throughout I highlight examples of case studies in evo devo and beyond that-by integrating a revised evaluation of the environment into their research programs-have been able to advance long-standing and critical questions in the biological sciences. I end by summarizing several theoretical frameworks that are already well in place to guide a more systemic re-integration of the role of environmental conditions in evo devo.

Keywords: genetic accommodation, developmental bias, niche construction, symbiosis, co-development

\section{THE GROWING SIGNIFICANCE OF THE ENVIRONMENT IN DEVELOPMENT AND EVOLUTION}

Recent years have witnessed a growing appreciation of the role of environmental conditions in shaping developmental processes and their outcomes (West-Eberhard, 2003; Gilbert and Epel, 2009; Gerhart and Kirschner, 2010). This constitutes a major step forward, away from the simplistic view still well-engrained in traditional evolutionary biology that environmental conditions function solely as an external agent of selection. In this review I argue that this re-evaluation of the environment and what it is and does in development, and by extension evolution, needs to continue. Specifically, I posit that existing empirical data are already sufficient to force a further expansion of our current definitions of the environment, that doing so would enable the field of evolutionary developmental biology to contribute meaningful answers to fundamental question of both basic and applied significance, and that several theoretical frameworks are already well in place to guide such a reorientation. I will begin by discussing where our current views of what constitutes environment in biology are increasingly challenged by biological reality.

\section{ENVIRONMENT AND SELECTABLE VARIATION}

Much of biology has long accepted that phenotypic variation is shaped by the interactions between genetic and environmental influences on phenotype formation, rather than being predetermined by an inflexible genome. As a consequence we now routinely integrate $\mathrm{G} \times \mathrm{E}$ interactions into quantitative genetic models, we understand that the penetrance of mutant phenotypes is affected by rearing environment (e.g., Shields and Harris, 2000; Cook et al., 2005; Martin and Lenormand, 2006), and that trait heritabilities have a tendency to increase in more stressful conditions (Gibson and Dworkin, 2004; Schlichting, 2008). In all these contexts environmental conditions have the potential to alter how genetic variation manifests in phenotypic, and thus selectable variation. More recently, however, a growing body of work has begun to suggest that this environmental influence on genotype-phenotype relationships may be neither modest nor rare: instead, laboratory and, increasingly, field studies illustrate that populations can harbor remarkable reserves of genetic variation, held in a cryptic, phenotypically unexpressed state as development unfolds in regular environmental conditions, but manifest in phenotypic variants when forced to occur in novel or stressful conditions (reviewed in Ledon-Rettig et al., 2014; Paaby and Rockman, 2014). While most of the released variation is expected to be neutral or even detrimental, this process has the potential to also increase the pool of putatively adaptive variants (Snell-Rood et al., 2010). This, in turn, raises the possibility that populations' abilities to respond to selection, and the direction of such responses, may not just depend on their mutational variation per se, but also, or maybe even more so, on the environmental conditions their developing members find themselves in.

\section{ENVIRONMENTS AS PHENOTYPES}

We commonly partition environmental and genetic effects in development. Even though both interact in practice, as emphasized above, we consider them separable in principle. A closer look at development in action, however, highlights the limitations of such a perspective. For example, whatever transcriptional and translational events take place in a given cell are influenced by the specific cellular environments that cell finds itself in, characterized for instance by the presence or absence of key resources such as microRNAs, transcription factors, nutrients, signals from neighboring cells, and other signatures of past developmental events. While many of these components of the nuclear and cellular environment involved the earlier expression of specific genes, at any given developmental time they collectively make up an environment that defines the developmental context within which a given cell finds itself and to which it responds by altering its transcriptional or translational activity, thereby again shaping the 
environmental conditions in which the same cell will find itself later in development (Moss, 2001).

This interdependency between genetic and environmental contributions to phenotype formation persists, perhaps even increases, across levels of biological organization. For example, the prevailing sensory environment experienced during development influences whether synapse formation during nervous system differentiation is reinforced or not, which in turn influences which sensory environment is perceived at later developmental stages (Kolb and Whishaw, 1998; Levitt et al., 1998; Rampon and Tsien, 2000; Baroncelli et al., 2010). Gut formation and differentiation from invertebrates to vertebrates responds to dietary conditions, which in turn affects the future dietary environments the developing organism experiences (Agrawal et al., 2002; Ledon-Rettig et al., 2008; Christeller et al., 2010; Saikia et al., 2011; Bloom et al., 2013). Across development, and across levels of biological organization, it is the environment generated by the cell, the organ, the ontogenetic stage, but also the partner or the social group that affects gene expression. At the same time it is the expression of these genes and their products that facilitate the creation of each of these environments. Viewed this way, the relationship between genes and environment is more than just interactive: instead genes and environment become interdependent, cause and effect of each other (Oyama, 1985; Keller, 2010).

On some level, we fully acknowledge the developmental origin of environments, and their ability to influence subsequent developmental events. For example, developmental biologists investigate the "stem cell niche" a specific anatomic location that regulates when and how stem cells participate in tissue generation, maintenance, and repair, guided by cell-cell interactions, extracellular matrix components, oxygen availability, growth factors, etc. (Scadden, 2006). Here it is understood that developmental processes create a developmental environment or "niche" critical for subsequent developmental events to unfold. Similarly, behavioral ecologists have long recognized that the cumulative actions of individuals within a group, most obvious in the context of parental care or herd behavior, create environmental conditions absolutely critical for normative offspring development to occur (Champagne, 2008; Rilling and Young, 2014). However, for the most part the interdependencies between development and environment remain to be broadly integrated in biology.

\section{ORGANISMS AS ENVIRONMENTS}

Recent years have seen an explosion of research findings that increasingly question our definition of the individual organism as a unit in development and evolution (Gilbert and Epel, 2009; Gilbert et al., 2012; McFall-Ngai et al., 2013). Instead, it appears that wherever we turn, what we perceive as the individual reveals itself as a team of interacting taxa: for example, gut microbiomes have emerged as critical interfaces between nutrition, growth, and intestinal disease from invertebrates to humans (Zhu et al., 2011; Flint, 2012; Devkota and Chang, 2013). Microorganisms play critical roles in immune function across taxa (e.g., Kau et al., 2011; Weinstock and Elliott, 2014), the decision where or where not to settle as mobile larvae turn into sessile adults rests at least in part on the specific endosymbionts involved (Whalan and Webster,
2014), and whether species can form viable hybrids or not may depend on the compatibility of their respective microbial partners (Brucker and Bordenstein, 2013).

In certain contexts, biologists have long recognized the importance of other organisms in influencing selective environments and subsequent evolutionary responses: for example, hostparasite dynamics are understood to be as complex as they are partly because of the properties that emerge from the reciprocal interactions between hosts and their co-evolving diseases (e.g., Auld et al., 2014). Yet there is growing recognition that host-symbiont interactions add layers of complexity that go wellbeyond what biologists are accustomed to: microbial interactions appear ubiquitous not just across taxa but also across developmental, physiological, and ecological contexts; endosymbionts provide additional avenues for trait inheritance and rapid adaptation; and lastly, host symbiont interactions may play critical roles in reciprocally shaping the environmental conditions in which each participating member finds itself (Gilbert and Epel, 2009; Gilbert et al., 2012; McFall-Ngai et al., 2013).

Collectively, the environment thus emerges (i) as a determinant of selectable phenotypic variation, (ii) as a cause and consequence of development, and (iii) as something that is shaped to a significant degree by host-microbe interactions. Taken together this questions our intuitive notions of environment as separable from-and external to-organisms, as a selective force that is passive rather than generative, and as an external agent that organisms respond to, rather than one that organisms actively modify to suit their responses. In the next section I will discuss why contemporary evo devo research stands to benefit greatly from integrating this re-evaluation of the environment into its research programs.

\section{RE-EVALUATING THE ENVIRONMENT-WHY DO WE CARE?}

Evo devo seeks to understand why and how developmental evolution unfolds the way it does and strives to identify the mechanisms that enable, channel, or impede developmental innovation and diversification (Raff, 1996, 2000). I posit that achieving these core objectives will benefit from, and in fact require, a more deliberate and systemic integration of the role of the environment, as detailed next.

\section{DEVELOPMENTAL PLASTICITY AND DEVELOPMENTAL BIAS IN EVO DEVO}

A growing body of studies illustrate that environmental conditions influence whether or not genetic variants will be phenotypically manifest and thus selectable (reviewed in Paaby and Rockman, 2014). It is also clear that the degree to which environmental conditions exert this influence on genotype-phenotype relations varies as a function of trait type, taxon, developmental stage, etc. and thus constitutes an influence that will have to be determined on a case by case basis (Ledon-Rettig et al., 2014). Nevertheless, the phenomenon as such necessitates a shift in our thinking about what is phenotypically possible in evolution away from mutational and recombinatorial variation as the main determinants and toward developmental systems: the sum total of all developmental and physiological processes, their products, and their interaction, including the integration of genetic 
and environmental inputs. While more complex, such a perspective offers fresh and possibly more productive lines of inquiry to address diverse questions of both fundamental as well as applied significance.

For instance, one of the most fundamental questions in evolutionary biology concerns the origin of novel complex traits and major transitions in evolution (reviewed in Moczek, 2008). Major transitions in evolution, by definition, reflect significant departures from ancestral variation, yet our search for mutations and genes that facilitated the initial origin of the first eye or wing, or the transition from water to land, or solitary to eusocial life have overall been frustrating. While we have been able to clearly associate important genetic contributions to present day manifestations of each of these major innovations (e.g., Shubin et al., 2009), exactly what it took to initiate these transitions in the first place, and why they occurred when they did, remains poorly understood. Most importantly, data are generally lacking that would support conceptualizing major evolutionary transitions as events that could be accomplished solely by accumulating one fortunate mutation at a time.

Here, a developmental systems perspective has been able to contribute fresh new insights, allowing us to move rather quickly beyond traditional roadblocks. Specifically, by investigating the interplay between developmental processes and the environmental conditions within which they occur diverse studies have been able to show that when forced to contend with novel or stressful conditions, pre-existing plasticity allows development to alter its products, revealing novel phenotypic variation in the process. For example, tadpoles from a lineage specialized to feed on detritus will, when forced to contend with a carnivorous diet, respond developmentally by altering their gut morphology, including responses in a direction identical to what is seen in lineages that have evolved a specialized carnivorous habit (Ledon-Rettig et al., 2010). Similarly, Polypterus fish are positioned taxonomically such that they are a good proxy for ancestral stem tetrapods prior to the water-land transition, and use their pectoral fins to both swim as well as "walk" on the sediment. When forced to develop in a "terrestrialized" environment (enough humidity to breathe, but not enough water to swim), fish develop more efficient gaits, upright postures, as well as skeletal arrangements that improved their ability to move in a more land-like environment (Standen et al., 2014). And a large series of independent studies have now shown that exposure to heat stress (or compromising the ability to deal with heat stress) results in the expression of a wide range of phenotypic variants normally rare or absent from natural populations (Rutherford and Lindquist, 1998; Queitsch et al., 2002; Cowen and Lindquist, 2005; Suzuki and Nijhout, 2006; see also Tirosh et al., 2010; Ruden, 2011; Rohner et al., 2013; Takahashi, 2013).

Importantly, in most of these cases, environmental conditions not only revealed novel phenotypic variation, but released corresponding genetic variation in the process, resulting for instance in increased heritabilities of gut traits in tadpoles (Ledon-Rettig et al., 2010) or ample variation to fuel rapid responses to artificial selection in flies (Rutherford and Lindquist, 1998) and butterflies (Suzuki and Nijhout, 2006). Studies such as these raise the possibility that major innovations and transitions in evolution may take their baby steps not just one mutation at a time, but in addition (or perhaps instead) one developmental response to novel environmental conditions at a time, with previously cryptic as well as newly arriving mutations subsequently stabilizing the most adaptive variants (Oyama, 1985; West-Eberhard, 2003).

A developmental systems perspective may be equally relevant for our ability to understand and predict short-term responses to rapid, anthropogenic changes to the environment. For example, increased drought frequencies have resulted in seasonally advanced production of white spruce cones. North American red squirrels critically depend on this food source, and in response to this temporal shift in resource availability have advanced their parturition dates by 18 days without a loss in mean lifetime reproductive success over only one decade, with much of this response due to phenotypic plasticity (Reale et al., 2003; Reed et al., 2011). Similarly, the house finch, Carpodacus mexicanus, managed to successfully colonize a remarkable range of environments during its recent invasion of North America. Descendant populations now exhibit extensive differentiation in physiological responses to environmental variation, including the induction of incubating behavior in response to temperature variation, which have been fine-tuned from plastic ancestors to produce local adaptation, generating populations with divergent reproductive phenotypes after only 14 generations (Badyaev, 2009).

Taken together, it is thus becoming increasingly clear that one of the chief objectives of evo devo, to understand how the nature of development biases evolutionary trajectories, cannot be accomplished without explicit consideration of environmental conditions. To develop is to interact with the environment. To evolve is to alter these interactions in a heritable manner.

\section{EVOLVING ENVIRONMENTS}

We traditionally view the environment as an external agent of selection, one that organisms respond to evolutionarily by evolving adaptations, and/or developmentally through evolved plastic responses to environmental influences. Through both mechanisms, an organism's fit to environmental conditions is enhanced and fitness losses are reduced. This perspective is challenged by the growing appreciation that organisms, rather than adjusting their traits to suit their environment, readily alter their environment to suit their traits (Odling-Smee, 2010). Furthermore, we have come to realize that such environment-alteration, or niche construction, can easily span generations (e.g., via parental care or long term habitat conditioning) and occur on any level of biological organization (e.g., from social groups to maternally transmitted antibodies). As such, organism-constructed environments may be best viewed as a type of extended phenotype with the potential to be heritable across generations, and thus capable of evolutionary change (Laland et al., 2014).

Recognizing environmental conditions as a potentially coevolving component of the organism has the potential to complicate our investigation into the causes, mechanisms, and consequences of developmental evolution. Already, ecological and population-genetic models that incorporate environmentmodifying behaviors illustrate that doing so can maintain genotypes that would otherwise be lost, significantly alter long-term evolutionary dynamics, facilitate the evolution of cooperation, 
enable organisms to persist in inhospitable environmental conditions, and alter carrying capacities, species richness and ecosystem robustness. (Laland et al., 1996, 1999, 2001; Kerr et al., 1999; Silver and Di Paolo, 2006; Lehmann, 2007, 2008; Kylafis and Loreau, 2008; Krakauer et al., 2009; Creanza et al., 2012; Van Dyken and Wade, 2012). At the same time, however, recognizing environments as partly constructed by organisms provides valuable new opportunities to revisit long-standing questions in evolutionary developmental biology.

For instance, evolutionary radiations are commonly conceptualized as the invasion of uninhabited niches, often leaving unanswered questions such as to why certain radiations occurred when they did and not earlier, or why certain clades rather than others radiated into specific niches (Laland et al., 2014). Recognizing organism driven environment-construction opens the possibility to view novel niches and radiation opportunities as something organisms actively created through their cumulative actions over time, such as shell beds and coral reefs, or the cumulative effects of filter feeders on the physical and chemical characteristics of water, or the effects of microbial communities or earthworms on soils (Odling-Smee, 2010). Such niche construction, often referred to as "ecosystem engineering" in this context, may be especially powerful because it can result in positive feedbacks, with certain environmental modifications altering selective conditions such that further ecosystem modifications in the same direction are favored. For instance, ocean oxygenation through sponges during the Ediacaran contributed to a change in redox conditions critical for the subsequent radiation of benthic organisms, driving further oxygenation. Similarly, the reworking of soils and sediments by burrowing animals, or bioturbation, greatly facilitated an increase in marine microbial biomass, thereby providing additional resources for burrowing animals, leading to further bioturbation (Erwin, 2005, 2008; Erwin and Valentine, 2013). On the other end of the geological time sale, recognizing environmental conditions as a potentially co-evolving with their organism may increase our ability to understand and predict how and why present-day populations and communities are responding to global climate change the way they do.

\section{CO-DEVELOPMENT AND THE DEVELOPMENTAL CAUSES OF DISEASE}

The above arguments apply of course similarly, if not more so, to instances in which other organisms constitute critical components of a focal organism's environment. Here, we have long understood that close fitness interdependencies beget co-evolution, whether in the context of predator-prey-, plantpollinator-, or host-parasite-systems. Lately, however, we had to revise our understanding of exactly how widespread, complex, and potentially impact-rich especially host-microbe interactions are, and the diversity of levels of biological organization on which they operate. For example, Asobara wasps will not form ovaries without signals from Wolbachia (Pannebakker et al., 2007), mice and zebrafish do not form normal guts without symbiotic bacteria (Hooper et al., 2001; Stappenbeck et al., 2002; Rawls et al., 2004; Mazmanian et al., 2005), and marine invertebrates fail to identify proper colonization sites unless guided by microbial partners (Whalan and Webster, 2014). The diversity of roles played by symbionts to guide development and physiology is truly astounding, and it extends well into human biology, with clear and critical implications for our understanding of the causes of pathology, and the design of treatments (McFall-Ngai et al., 2013). For example, it is now understood that the protein deficiency that causes kwashiorkor only manifests when certain gut bacteria are present (Smith et al., 2013) and that recurrent ulcerative colitis caused by Clostridium difficile infections of the gut can be stopped by inoculating patients with dilute fecal samples from healthy donors (Russell et al., 2010; Silverman et al., 2010).

Similarly, a growing list of autoimmune diseases are now increasingly recognized, at least in part and at least in some patient populations, as a manifestation of an immune system deprived of the natural range of challenges it evolved to respond to due to hygiene measures such as flush toilets, the absence of parasites, and the widespread use of antibiotics in everyday consumables (von Mutius, 2007). This hygiene hypothesis focuses on the nature of relationships and interactions between humans and the biotic environment with which we have co-evolved, and opens the door to understand the emergence of disease without the requirement for the existence of new genes or gene variants causing the disease. Instead, it predicts that restoring aspects of past interactions with the environment may have the potential to calm overreacting immune systems into more measured responses (Bilbo et al., 2011; Fleming, 2011). Growing support exists for the validity of such an approach: for example, inoculation with helminths successfully alleviated the symptoms of patients with asthma (Leonardi-Bee et al., 2006), inflammatory bowel disease (Summers et al., 2003; Bilbo et al., 2011), and multiple sclerosis (Fleming et al., 2011; Fleming, 2013), and non-obese diabetic mice normally fated to develop Type 1 diabetes failed to do so following pig whipworm infections (Cooke et al., 1999; Zaccone et al., 2003). Collectively, these studies provide growing support that co-development with microbial or infectious agents may be key to creating internal environments critical for normative development, including our own (reviewed in Zaccone et al., 2006; Weinstock and Elliott, 2014).

\section{RE-EVALUATING THE ENVIRONMENT—CONCEPTUAL STARTING POINTS}

The preceding paragraphs tried to make the case that a growing body of evidence is increasingly questioning the intuitive boundaries we draw around organisms and their environments, and the respective attributes we attach. With environments being constructed by organisms themselves, and thus heritable and evolving, by environments enabling organismal development and vice versa, and by many organisms being both organism and critical part of the environment at the same time, our old dichotomies are having a hard time catching up. I would therefore like to end this essay by highlighting several powerful conceptual frameworks that have emerged in evo devo's vicinity that already provide productive ways to incorporate the growing complexity of organism-environment interdependence into meaningful experimental frameworks.

\section{THE THEORY OF EVOLUTION BY GENETIC ACCOMMODATION}

The theory of evolution by genetic accommodation, developed by West-Eberhard $(2003,2005)$ posits that environmental 
conditions, acting through development, can elicit phenotypic transformations that can subsequently be stabilized genetically through selection operating on genetic variation in a population. This genetic variation may derive from pre-existing heritable variation, previously cryptic generic variants, or mutations arriving anew. That evolution by genetic accommodation can occur is now without doubt: lab-and increasingly field studies have demonstrated the at times surprising power of environmental conditions in revealing novel and selectable phenotypic variation (reviewed in Pfennig et al., 2010; Moczek et al., 2011; Schlichting and Wund, 2014). As such, evolution by genetic accommodation is well on its way to being integrated into conventional evolutionary biology, the resistance of some notwithstanding (Wray et al., 2014). Its arguably most significant contribution is the realization that many novel traits or variants derive originally from ancestral plastic responses, i.e., were expressed initially as environmentally induced, conditional alternatives to established traits (Pfennig et al., 2010). While much research in evolutionary biology and evo devo continues to focus on identifying genes for key innovations, genetic accommodation theory broadens our perspective toward exploring gene functions and interactions in the context of changing internal and external environmental conditions.

\section{THE MORPHOLOGY OF DEVELOPMENT AND THE THEORY OF FACILITATED VARIATION}

Formulated by Kirschner and Gerhart (2005) and Gerhart and Kirschner $(2007,2010)$ the theory of facilitated variation represents the most rigorous attempt to date to confront our lack of understanding of the origins of novel, functional, and complex traits with the most important insights that molecular, cellular, and developmental biology have generated over recent decades on how cells, tissues, organs, and organisms build and maintain themselves. This framework developed mostly outside an evo devo context and remains to be integrated, but has much to offer toward its future as we are trying to understand developmentenvironment interactions, and how these in turn shape, and are shaped by, organismal evolution.

Central to this framework is the realization that multicellular organisms rely on a set of highly conserved core processes, ranging from e.g., transcription and translation to microtubule and synapse formation to the formation of neuronal connections in the brain and muscular-skeletal connections. Many of these processes share a propensity for exploratory behavior which is then followed by periods of somatic selection of the most functional state. For instance, microtubules initially grow and shrink randomly into cytoplasmic space until polarized by stabilizing signals and muscle precursor cells migrate randomly during early development but are maintained into later stages only if they manage to innervate muscles. The same theme emerges when other core processes are examined, such as the development of neural and vascular systems: all select and stabilize certain states over others following periods of exploratory behavior (reviewed by Alonzo et al., 2011; Herring, 2011; Kovach et al., 2011).

At the same time, conserved core processes are characterized by weak linkage to the signals that regulate their activity as well as other developmental processes with which they interact, causing any specific signal to have an easily altered relationship to the specific developmental outcome it solicits. For instance, a great diversity of sensory inputs can bring about, via the same highly conserved neuronal machinery, a great diversity of motor functions. The same, highly conserved cellular transduction pathways connect an enormous wealth of external inputs to internal outputs. And the same, highly conserved endocrine machinery enables the linking of diverse external signals to equally diverse behavioral, physiological, and developmental responses (Nijhout, 1994; Hartfelder and Emlen, 2005; Alberts et al., 2008).

Combined, exploratory behavior and weak linkage enable developmental processes to be adaptably responsive to conditions. As such, development facilitates ontogenetic change because it can adjust to context. Development facilitates evolutionary change because it enables random perturbations, including those provided by novel mutations, to give rise to non-random, functional, integrated, and on occasion adaptive, phenotypic variations. Because of the highly constrained nature of its constituent core processes, their respective specific developmental functions are ensured regardless of context. But at the same time, due to exploratory behavior and weak linkage, the emergence of novel and sometimes adaptive phenotypic variation is deconstrained (Kirschner and Gerhart, 2005; Gerhart and Kirschner, 2007, 2010).

The theory of facilitated variation generates important opportunities for evo devo research as it forces a more biologically realistic understanding of the genotype-phenotype relationship. First, it views phenotypes as rooted in development rather than genes and genetic variation. The latter clearly make a difference, but they do not-by themselves-allow phenotypes to emerge. Second, it provides a framework for understanding the mechanisms by which alterations of development brought about by e.g., changes in ecological conditions or the introduction of novel genetic variation can elicit non-random and integrated phenotypic changes, chaperoned by the facilitating nature of development. As such it provides a useful new way of thinking about the mechanisms that allow development to be sensitive to the environment, environment-sensitivity to evolve, and novel yet functional phenotypic variation to emerge in the process.

\section{WHEN ORGANISMS MAKE ENVIRONMENTS, AND ENVIRONMENTS CAN EVOLVE-THE PROMISE OF NICHE CONSTRUCTION THEORY}

Niche construction theory is a mature, quantitative, theoretical framework which nevertheless remains to be fully integrated in ecology and evolution, yet has perhaps most to offer to evo devo practioners (Laland et al., 2014). Niche construction focuses on the interplay between organisms and their ecological niches, positing that organisms actively construct their niches, which in turn affect organisms' development and evolution (Lewontin, 1983; Odling-Smee, 2010). Niche construction theory has enabled biologists to rephrase and extend key concepts in evolutionary biology: for example, niche construction theory allows adaptation to be understood as emerging not just from organisms responding to the environment, but modifying their environment in ways that suit their responses. Similarly, niche construction theory allows selective environments to be understood as being moving targets, evolving in concert with a 
population of organisms that is adapting to them (Laland et al., 1999, 2001, 2014). On both fronts, niche construction theory links well to the theory of facilitated variation. While focusing on different levels of biological organization, there is no reason why niches and environments must exist solely outside the body or why their construction cannot occur during any stage of development (Moczek, 2012). In both frameworks, entire organisms as well as their organs, cells, or signal transduction pathways actively construct environments that enable subsequent adaptive responses.

Collectively all three theoretical frameworks highlighted here expand the way evo devo research can formulate empirical approaches to long-standing questions. Specifically, they force the realization that any novel trait, any putative adaptation, and any plastic response begins with a gene only if we so chose to start our investigation at this point. This is not to say that identifying differentially expressed or re-deployed genes and pathways is a bad starting point-but if our goal is to understand how organismal complexity comes into being, and when it does so, the environment-dependent nature of development and developmental evolution deserve to take center stage.

\section{CONCLUSIONS}

A mounting body of evidence across the tree of life shows that organisms execute their development in tight interdependence with the environment, with significant aspects of the environment being both cause and effect of organismal development, shaping and directing how and when, and with what consequences, genetic programs are allowed to unfold. Evo devo has long prided itself, and rightfully so, by conceptualizing evolutionary change not as an abstract change in gene frequencies, but as a much more biologically meaningful change in developmental processes over time. By realizing that organismal development and environment are quite often impossible to divorce, it is time for evo devo to expand its conceptualization of evolution once more. Already, several studies suggest that integrating the environmentdependent nature of development and developmental evolution into evo devo research programs critically advances key frontiers in the biological sciences, from our understanding of the genesis of novel complex traits and the biological future of a changing planet to the developmental causes of disease.

\section{ACKNOWLEDGMENTS}

Sofia Casasa, Cris Ledón-Rettig, Daniel Schwab, and two anonymous reviewers provided helpful comments on earlier drafts of this manuscript.

\section{REFERENCES}

Agrawal, A. A., Vala, F., and Sabelis, M. W. (2002). Induction of preference and performance after acclimation to novel hosts in a phytophagous spider mite: adaptive plasticity? Am. Nat. 159, 553-565. doi: 10.1086/339463

Alberts, B., Johnson, A., Lewis, J., Raff, M., and Walter, P. (2008). Molecular Biology of the Cell. New York, NY: Garland Science.

Alonzo, M., Smith, K. K., and Kirby, M. L. (2011). "Epigenetic interactions of the cardiac neural crest," in Epigenetics: Linking genotype and Phenotype in Development and Evolution, eds B. Hallgrímsson and B. K. Hall (Berkeley, CA: University of California Press), 181-94.

Auld, S. K., Hall, S. R., Housley Ochs, J., Sebastian, M., and Duffy, M. A. (2014). Predators and patterns of within-host growth can mediate both among-host competition and evolution of transmission potential of parasites. Am. Nat. 184, S77-S90. doi: 10.1086/676927

Badyaev, A. (2009). Evolutionary significance of phenotypic accommodation in novel environments: an empirical test of the Baldwin effect. Phil. Trans. R. Soc B 364, 1125-1141. doi: 10.1098/rstb.2008.0285

Baroncelli, L., Braschi, C., Spolidoro, M., Begenisic, T., Sale, A., and Maffei, L. (2010). Nurturing brain plasticity: impact of environmental enrichment. Cell Death Differ. 17, 1092-1103. doi: 10.1038/cdd.2009.193

Bilbo, S. D., Wray, G. A., Perkins, S. E., and Parker, W. (2011). Reconstitution of the human biome as the most reasonable solution for epidemics of allergic and autoimmune diseases. Med. Hypotheses 77, 494-504. doi: 10.1016/j.mehy.2011.06.019

Bloom, S., Ledon-Rettig, C., Infante, C., Everly, A., Hanken, J., and Nascone-Yoder N. (2013). Developmental origins of a novel gut morphology in frogs. Evol. Dev. 15, 213-223. doi: 10.1111/ede. 12035

Brucker, R. M., and Bordenstein, S. R. (2013). The hologenomic basis of speciation: gut bacteria cause hybrid lethality in the genus Nasonia. Science 341, 667-669. doi: 10.1126/science.1240659

Champagne, F. A. (2008). Epigenetic mechanisms and the transgenerational effects of maternal care. Front. Neuroendocrinol. 29, 386-397. doi: 10.1016/j.yfrne.2008.03.003

Christeller, J. T., Poulton, J., Markwick, N. M., and Simpson, R. M. (2010). The effect of diet on the expression of lipase genes in the midgut of the lightbrown apple moth (Epiphyas postvittana Walker; Tortricidae). Insect Mol. Biol. 19, 9-25. doi: 10.1111/j.1365-2583.2009.00924.x

Cook, J. D., Davis, B. J., Cai, S. L., Barrett, J. C., Conti, C. J., and Walker, C. L. (2005). Interaction between genetic susceptibility and early-life environmental exposure determines tumorsuppressor- gene penetrance. Proc. Natl. Acad. Sci. U.S.A. 102, 8644-8649. doi: 10.1073/pnas.0503218102

Cooke, A., Tonks, P., Jones, F. M., O’Shea, H., Hutchings, P., Fulford, A. J., et al. (1999). Infection with Schistosoma mansoni prevents insulin dependent diabetes mellitus in non-obese diabetic mice. Parasite Immunol. 21, 169-176. doi: 10.1046/j.1365-3024.1999.00213.x

Cowen, L. E., and Lindquist, S. (2005). Hsp90 potentiates the rapid evolution of new traits: drug resistance in diverse fungi. Science 309, 2185-2189. doi: 10.1126/science. 1118370

Creanza, N., Fogarty, L., and Feldman, M. W. (2012). Models of cultural niche construction with selection and assortative mating. PLoS ONE 7:e42744. doi: 10.1371/journal.pone.0042744

Devkota, S., and Chang, E. B. (2013). Nutrition, microbiomes, and intestinal inflammation. Curr. Opin. Gasteroeneterol. 29, 603-607. doi: 10.1097/MOG.0b013e328365d38f

Erwin, D. H. (2005). Seeds of diversity. Science 308, 1752-1753. doi: 10.1126/science. 1113416

Erwin, D. H. (2008). Macroevolution of ecosystem engineering, niche construction and diversity. Trends Ecol. Evol. 23, 304-310. doi: 10.1016/j.tree.2008. 01.013

Erwin, D. H., and Valentine, J. W. (2013). The Cambrian Explosion: The Construction of Animal Biodiversity. Greenwood, CO: Roberts \& Company.

Fleming, J. O. (2011). Helminths and multiple sclerosis: will old friends give us new treatments for MS? J. Neuroimmunol. 233, 3-5. doi: 10.1016/j.jneuroim.2011.01.003

Fleming, J. O. (2013). Helminth therapy and multiple sclerosis. Int. J. Parasitol. 43, 259-274. doi: 10.1016/j.ijpara.2012.10.025

Fleming, J. O., Isaak, A., Lee, J. E., Luzzio, C. C., Carrithers, M. D., Cook, T. D., et al. (2011). Probiotic helminth administration in relapsing-remitting multiple sclerosis: a phase 1 study. Mult. Scler. J. 17, 743-754. doi: $10.1177 / 1352458511398054$

Flint, H. J. (2012). The impact of nutrition on the human microbiome. Nutr. Rev. 70(Suppl. 1), S10-S13. doi: 10.1111/j.1753-4887

Gerhart, J. C., and Kirschner, M. W. (2007). The theory of facilitated variation. Proc. Natl. Acad. Sci. U.S.A. 104, 8582-8589. doi: 10.1073/pnas.0701035104

Gerhart, J. C., and Kirschner, M. W. (2010). "Facilitated variation," in Evolution: the Extended Synthesis, eds M. Pigliucci and B. G. Mueller (Cambridge, MA: MIT press), 253-80.

Gibson, G., and Dworkin, I. (2004). Uncovering cryptic genetic variation. Nat. Rev. Genet. 5, 681-690. doi: 10.1038/nrg1426

Gilbert, S. F., and Epel, D. (2009). Ecological Developmental Biology: Integrating Epigenetics, Medicine, and Evolution. Sunderland, MA: Sinauer Associates, Inc. 
Gilbert, S. F., Sapp, J., and Tauber, A. I. (2012). A symbiotic view of life: we have never been individuals. Q. Rev. Biol. 87, 325-341. doi: 10.1086/668166

Hartfelder, K., and Emlen, D. J. (2005). Endocrine control of insect polyphenism. Compr. Mol. Insect Sci. 3, 651-703. doi: 10.1016/B0-44-451924-6/ 00045-4

Herring, S. W. (2011). "Muscle-bone interactions and the development of skeletal phenotype: jaw muscles and the skull," in Epigenetics: Linking Genotype and Phenotype in Development and Evolution, eds B. Hallgrímsson and B. K. Hall (Berkeley, CA: University of California Press), 221-237.

Hooper, L. V., Wong, M. H., Thelin, A., Hansson, L., Falk, P. G., and Gordon, J. I. (2001). Molecular analysis of commensal host-microbial relationships in the intestine. Science 291, 881-884. doi: 10.1126/science.291.5505.881

Kau, A. L., Ahern, P. P., Griffin, N. W., Goodman, A. L., and Gordon, J. I. (2011). Human nutrition, the gut microbiome and the immune system. Nature 474, 327-336. doi: 10.1038/nature10213

Keller, E. F. (2010). The Mirage of a Space Between Nature and Nurture. Durham, NC: Duke University Press. doi: 10.1215/9780822392811

Kerr, B., Schwilk, D. W., Bergman, A., and Feldman, M. W. (1999). Rekindling an old flame: a haploid model for the evolution and impact of flammability in resprouting plants. Evol. Ecol. Res. 1, 807-833.

Kirschner, M. W., and Gerhart, J. C. (2005). The Plausability of Life: Resolving Darwin's Dilemma. Yale University Press.

Kolb, B., and Whishaw, I. Q. (1998). Brain plasticity and behavior. Ann. Rev. Psychol. 49, 43-64. doi: 10.1146/annurev.psych.49.1.43

Kovach, C., Mattar, P., and Schuurmans, C. (2011). "The role of epigenetics in nervous system development," in Epigenetics: Linking Genotype and Phenotype in Development and Evolution, eds B. Hallgrímsson and B. K. Hall (Berkeley, CA: University of California Press), 137-163.

Krakauer, D. C., Page, K. M., and Erwin, D. H. (2009). Diversity, dilemmas, and monopolies of niche construction. Am. Nat. 173, 26-40. doi: 10.1086/593707

Kylafis, G., and Loreau, M. (2008). Ecological and evolutionary consequences of niche construction for its agent. Ecol. Lett. 11, 1072-1081. doi: 10.1111/j.14610248.2008.01220.x

Laland, K. N., Odling-Smee, F. J., and Feldman, M. W. (1996). The evolutionary consequences of niche construction: a theoretical investigation using two-locus theory. J. Evol. Biol. 9, 293-316. doi: 10.1046/j.1420-9101.1996.903 0293.x

Laland, K. N., Odling-Smee, F. J., and Feldman, M. W. (1999). Evolutionary consequences of niche construction and their implications for ecology. Proc. Natl. Acad. Sci. U.S.A. 96, 10242-10247. doi: 10.1073/pnas.96.18.10242

Laland, K. N., Odling-Smee, J., and Feldman, M. W. (2001). Cultural niche construction and human evolution. J. Evol. Biol. 14, 22-33. doi: 10.1046/j.14209101.2001.00262.x

Laland, K., Tobias, U., Feldman, M., Sterelny, K., Müller, G., Moczek, A. P., et al. (2014). Does evolutionary theory need a rethink? Nature 514, 161-164. doi: $10.1038 / 514161 \mathrm{a}$

Ledon-Rettig, C. C., Pfennig, D. W., and Crespi, E. J. (2010). Diet and hormonal manipulation reveal cryptic genetic variation: implications for the evolution of novel feeding strategies. Proc. Roy. Soc. B 277, 3569-3578. doi: 10.1098/rspb.2010.0877

Ledon-Rettig, C. C., Pfennig, D. W., and Nascone-Yoder, N. (2008). Ancestral variation and the potential for genetic accommodation in larval amphibians: implications for the evolution of novel feeding strategies. Evol. Dev. 10, 316-325. doi: 10.1111/j.1525-142X.2008.00240.x

Ledon-Rettig, C. C., Pfennig, D. W., Chunco, A. J., and Dworkin, I. (2014). Cryptic genetic variation in natural populations: a predictive framework. Integr. Comp. Biol. 54, 783-793. doi: 10.1093/icb/icu077

Lehmann, L. (2007). The evolution of trans-generational altruism: kin selection meets niche construction. J. Evol. Biol. 20, 181-189. doi: 10.1111/j.14209101.2006.01202.x

Lehmann, L. (2008). The adaptive dynamics of niche constructing traits in spatially subdivided populations: evolving posthumous extended phenotypes. Evolution 62, 549-566. doi: 10.1111/j.1558-5646.2007.00291.x

Leonardi-Bee, J., Pritchard, D., and Britton, J. (2006). Asthma and current intestinal parasite infection - Systematic review and meta-analysis. Am. J. Respir. Crit. Care Med. 174, 514-523. doi: 10.1164/rccm.200603-331OC

Levitt, P., Reinoso, B., and Jones, L. (1998). The critical impact of early cellular environment on neuronal development. Prev. Med. 27, 180-183. doi: 10.1006/pmed.1998.0273
Lewontin, R. C. (1983). "Gene, organism and environment," in Evolution from Molecules to Men, ed Derek S. Bendall (Cambridge, MA: Cambridge University Press), 273-285

Martin, G., and Lenormand, T. (2006). The fitness effect of mutations across environments: a survey in light of fitness landscape models. Evolution 60, 2413-2427. doi: 10.1554/06-162.1

Mazmanian, S. K., Liu, C. H., Tzianabos, A. O., and Kasper, D. L. (2005). An immunomodulatory molecule of symbiotic bacteria directs maturation of the host immune system. Cell 122, 107-118. doi: 10.1016/j.cell.2005.05.007

McFall-Ngai, M., Hadfield, M. G., Bosch, T. C., Carey, H. V., Domazet-Loso, T., Douglas, A. E., et al. (2013). Animals in a bacterial world, a new imperative for the life sciences. Proc. Natl. Acad. Sci. U.S.A. 110, 3229-3236. doi: $10.1073 /$ pnas. 1218525110

Moczek, A. P. (2008). On the origin of novelty in development and evolution. Bioessays 5, 432-447. doi: 10.1002/bies.20754

Moczek, A. P. (2012). The nature of nurture and the future of evo devo: toward a theory of developmental evolution. Integr. Comp. Biol. 52, 108-119. doi: 10.1093/icb/ics048

Moczek, A. P., Sultan, S., Foster, S., Ledon-Rettig, C., Dworkin, I., Nijhout, H. F., et al. (2011). The role of developmental plasticity in evolutionary innovation. Proc. Roy. Soc. B 278, 2705-2713. doi: 10.1098/rspb.2011.0971

Moss, L. (2001). "Deconstructing the gene and reconstructing molecular developmental systems," in Cycles of Contingency-Developmental Systems and Evolution, eds S. Oyama, P. Griffith, and R. Gray (Cambridge, MA: MIT Press), 85-97.

Nijhout, H. F. (1994). Insect Hormones. Princeton, NJ: Princeton University Press.

Odling-Smee, J. (2010). "Niche Inheritance," in Evolution: the Extended Synthesis, eds M. Pigliucci and G. Müller (Cambridge: The MIT Press), 175-208. doi: 10.7551/mitpress/9780262513678.003.0008

Oyama, S. (1985). The Ontogeny of Information: Developmental Systems and Evolution. Cambridge, MA: Cambridge University Press.

Paaby, A. B., and Rockman, M. V. (2014). Cryptic genetic variation: evolution's hidden substrate. Nat. Rev. Genet. 15, 247-258. doi: 10.1038/nrg3688

Pannebakker, B. A., Loppin, B., Elemans, C. P., Humblot, L., and Vavre, F. (2007). Parasitic inhibition of cell death facilitates symbiosis. Proc. Natl. Acad. Sci. U.S.A. 104, 213-215. doi: 10.1073/pnas.0607845104

Pfennig, D. W., Wund, M. A., Snell-Rood, E. C., Cruickshank, T., Schlichting, C. D., and Moczek, A. P. (2010). Phenotypic plasticity's impacts on diversification and speciation. Trends Ecol. Evol. 25, 459-467. doi: 10.1016/j.tree.2010.05.006

Queitsch, C., Sangster, T. A., and Lindquist, S. (2002). Hsp90 as a capacitor of phenotypic variation. Nature 417, 618-624. doi: 10.1038/nature749

Raff, R. A. (1996). The Shape of Life: Genes Development, and the Evolution of Animal Form.Chicago, IL: University of Chicago Press.

Raff, R. A. (2000). Evo-devo: the evolution of a new discipline. Nat. Rev. Genet. 1, 74-79. doi: 10.1038/35049594

Rampon, C., and Tsien, J. Z. (2000). Genetic analysis of learning behaviorinduced structural plasticity. Hippocampus 10, 605-609. doi: 10.1002/10981063(2000) 10:5<605::AID-HIPO11>3.0.CO;2-3

Rawls, J. F., Samuel, B. S., and Gordon, J. I. (2004). Gnotobiotic zebrafish reveal evolutionarily conserved responses to the gut microbiota. Proc. Natl. Acad. Sci. U.S.A. 101, 4596-4601. doi: 10.1073/pnas.0400706101

Reale, D., McAdam, A. G., Boutin, S., and Berteaux, D. (2003). Genetic and plastic responses of a northern mammal to climate change. Proc. Roy Soc. B 270, 591-596. doi: 10.1098/rspb.2002.2224

Reed, T. E., Schindler, D. E., and Waples, R. S. (2011). Interacting effects of phenotypic plasticity and evolution on population persistence in a changing climate. Conserv. Biol. 25, 56-63. doi: 10.1111/j.1523-1739.2010.01552.x

Rilling, J. K., and Young, L. J. (2014). The biology of mammalian parenting and its effect on offspring social development. Science 345, 771-776 doi: 10.1126/science. 1252723

Rohner, N., Jarosz, D. F., Kowalko, J. E., Yoshizawa, M., Jeffery, W. R., Borowsky, R. L., et al. (2013). Cryptic variation in morphological evolution: HSP90 as a capacitor for loss of eyes in cavefish. Science 342, 1372-1375. doi: 10.1126/science. 1240276

Ruden, D. M. (2011). The (new) new synthesis and epigenetic capacitors of morphological evolution. Nat. Genet. 43, 88-89. doi: 10.1038/ng0211-88

Russell, G., Kaplan, J., Ferraro, M., and Michelow, I. C. (2010). Fecal bacteriotherapy for relapsing Clostridium difficile infection in a child: a proposed treatment protocol. Pediatrics 126, E239-E242. doi: 10.1542/peds.2009-3363 
Rutherford, A. L., and Lindquist, S. (1998). Hsp90 as a capacitor for morphological evolution. Nature 396, 336-342. doi: 10.1038/24550

Saikia, M., Singh, Y. T., Bhattacharya, A., and Mazumdar-Leighton, S. (2011). Expression of diverse midgut serine proteinases in the sericigenous Lepidoptera Antheraea assamensis (Helfer) is influenced by choice of host plant species. Insect Mol. Biol. 20, 1-13. doi: 10.1111/j.1365-2583.2010.01048.x

Scadden, D. T. (2006). The stem-cell niche as an entity of action. Nature 441, 1075-1079. doi: 10.1038/nature04957

Schlichting, C. D. (2008). Hidden reaction norms, cryptic genetic variation, and evolvability. Ann. N.Y. Acad. Sci. 1133, 187-203. doi: 10.1196/annals. 1438.010

Schlichting, C. D., and Wund, M. A. (2014). Phenotypic plasticity and epigenetic marking: as assessment of evidence for genetic accommodation. Evolution 68, 656-672. doi: 10.1111/evo.12348

Shields, P. G., and Harris, C. C. (2000). Cancer risk and low-penetrance susceptibility genes in gen-environment interactions. J. Clin. Oncol. 18, 2309-2315.

Shubin, N., Tabin, C., and Carroll, S. (2009). Deep homology and the origins of evolutionary novelty. Nature 457, 818-823. doi: 10.1038/nature07891

Silver, M. and Di Paolo, E. (2006). Spatial effects favour the evolution of niche construction. Theor. Popul. Biol. 70, 387-400. doi: 10.1016/j.tpb.2006.08.003

Silverman, M. S., Davis, I., and Pillai, D. R. (2010). Success of self-administered home fecal transplantation for chronic Clostridium difficile infection. Clin. Gastroenterol. Hepatol. 8, 471-473. doi: 10.1016/j.cgh.2010.01.007

Smith, M. I., Yatsunenko, T., Manary, M. J., Trehan, I., Mkakosya, R., Cheng, J., et al. (2013). Gut microbiomes of Malawian twin pairs discordant for kwashiorkor. Science 339, 548-554. doi: 10.1126/science. 1229000

Snell-Rood, E. C., Van Dyken, J. D., Cruickshank, T., Wade, M. J., and Moczek, A. P. (2010). Toward a population genetic framework of developmental evolution: the costs, limits, and consequences of phenotypic plasticity. BioEssays 32, 71-81. doi: 10.1002/bies.200900132

Standen, E. M., Du, T. Y., and Larsson, H. C. E. (2014). Developmental plasticity and the origin of tetrapods. Nature 513, 54-58. doi: 10.1038/nature 13708

Stappenbeck, T. S., Hooper, L. V., and Gordon, J. I. (2002). Developmental regulation of intestinal angiogenesis by indigenous microbes via Paneth cells. Proc. Natl. Acad. Sci. U.S.A. 99, 15451-15455. doi: 10.1073/pnas.202604299

Summers, R. W., Elliott, D. E., Qadir, K., Urban, J. F. Jr., Thompson, R., and Weinstock, J. V. (2003). Trichuris suis seems to be safe and possibly effective in the treatment of inflammatory bowel disease. Am. J. Gastroenterol. 98, 2034-2041. doi: 10.1111/j.1572-0241.2003.07660.x

Suzuki, Y., and Nijhout, H. F. (2006). Evolution of a polyphenism by genetic accommodation. Science 311, 650-652. doi: 10.1126/science.1118888

Takahashi, K. H. (2013). Multiple capacitors for natural genetic variation in Drosophila melanogaster. Mol. Ecol. 22, 1356-1365. doi: 10.1111/mec.12091

Tirosh, I., Reikhav, S., Sigal, N., Assia, Y., and Barkai, N. (2010). Chromatin regulators as capacitors of interspecies variations in gene expression. Mol. Syst. Biol. 6, 435. doi: $10.1038 / \mathrm{msb} .2010 .84$
Van Dyken, J. D., and Wade, M. J. (2012). Origins of altruism diversity II: runaway coevolution of altruistic strategies via "reciprocal niche construction." Evolution 66, 2498-2513. doi: 10.1111/j.1558-5646.2012.01629.x

von Mutius, E. (2007). Allergies, infections and the hygiene hypothesis - The epidemiological evidence. Immunobiology 212, 433-439. doi: 10.1016/j.imbio.2007.03.002

Weinstock, J. V., and Elliott, D. E. (2014). Helminth Infections Decrease Host Susceptibility to Immune-Mediated Diseases. J. Immunol. 193, 3239-3247. doi: 10.4049/jimmunol.1400927

West-Eberhard, M. J. (2003). Developmental Plasticity and Evolution. Oxford: Oxford University Press.

West-Eberhard, M. J. (2005). Phenotypic accommodation: adaptive innovation due to developmental plasticity. J. Exp. Biol. B Mol. Dev. Evol. 304, 610-618. doi: 10.1002/jez.b.21071

Whalan, S., and Webster, N. S. (2014). Sponge larval settlement cues: the role of microbial biofilms in a warming ocean. Sci. Rep. 4:4072. doi: 10.1038/srep04072

Wray, G. A., Hoekstra, H. E., Futuyma, D. J., Lenski, R. E., Mackay, T. F. C., Schluter, D. E., et al. (2014). Does evolutionary theory need a rethink? COUNTERPOINT No, all is well. Nature 514, 161-164. doi: 10.1038/514161a

Zaccone, P., Fehérvári, Z., Jones, F. M., Sidobre, S., Kronenberg, M., Dunne, D. W., et al. (2003). Schistosoma mansoni antigens modulate the activity of the innate immune response and prevent onset of type 1 diabetes. Eur. J. Immunol. 33, 1439-1449. doi: 10.1002/eji.200323910

Zaccone, P., Fehlervari, Z., Phillips, J. M., Dunne, D. W., and Cooke, A. (2006). Parasitic worms and inflammatory diseases. Parasite Immunol. 28, 515 doi: 10.1111/j.1365-3024.2006.00879.x

Zhu, Y., Michelle Luo, T., Jobin, C., and Young, H. A. (2011). Gut microbiota and probiotics in colon tumorigenesis. Cancer Lett. 309, 119-127. doi: 10.1016/j.canlet.2011.06.004

Conflict of Interest Statement: The author declares that the research was conducted in the absence of any commercial or financial relationships that could be construed as a potential conflict of interest.

Received: 05 December 2014; paper pending published: 11 January 2015; accepted: 16 January 2015; published online: 05 February 2015.

Citation: Moczek AP (2015) Re-evaluating the environment in developmental evolution. Front. Ecol. Evol. 3:7. doi: 10.3389/fevo.2015.00007

This article was submitted to Evolutionary Developmental Biology, a section of the journal Frontiers in Ecology and Evolution.

Copyright $\odot 2015$ Moczek. This is an open-access article distributed under the terms of the Creative Commons Attribution License (CC BY). The use, distribution or reproduction in other forums is permitted, provided the original author(s) or licensor are credited and that the original publication in this journal is cited, in accordance with accepted academic practice. No use, distribution or reproduction is permitted which does not comply with these terms. 